\title{
A Agenda Social do MERCOSUL: a Relação Estado Nacional e Integração Regional
}

\author{
Lúcia Cortes da Costa*
}

\begin{abstract}
Resumo: o artigo analisa o Estado nacional e suas transformações com a criação de espaços supranacionais, sugerindo possíveis desdobramentos do processo de integração regional para formulação e efetivação de políticas sociais. Parte da hipótese de que as transformações desencadeadas pela internacionalização da economia afetam os espaços políticos, redefinindo os Estados nacionais. A construção de mecanismos supranacionais já é identificada na área do comércio, porém no campo das políticas sociais ainda não se têm experiências de instituições supranacionais que operem na garantia dos direitos sociais. O MERCOSUL nasceu com claros objetivos comerciais. No en-tanto, avançou para uma agenda social que se propõe, ao menos no plano discursivo, à construção de um modelo comum de atuação na área social, com harmonização da legislação trabalhista, previdenciária, propondo a construção de uma cidadania comunitária. O estudo problematiza essa agenda social e conclui apresentando ponderações sobre a possibilidade de se pensar em um padrão de proteção social comum aos cidadãos do bloco regional e a necessidade de mecanismos para a garantia dos direitos sociais.
\end{abstract}

Palavras-chave: Estado; proteção social; cidadania; MERCOSUL.

\begin{abstract}
This article is methodologically grounded in a conceptual deductive hypothetical approach of the main ideas concerning social rights and MERCOSUL. It discusses the transformations which take place in the national state through the creation of beyond border spaces and its influence in the establishment and development of social politics. The main hypothesis supports the idea that the transformations from economic internationalization of the state shape the policy making and the state by itself. In the social politics field of the MERCOSUL there are no international guidelines related to social rights - this occurs only in the trade area. Despite clear commercial means from MERCOSUL, there is a social agenda (at least in rhetoric plan) which demands the construction of a common model for social area linked with work legislation, social security and the construction of communitarian citizenship. From all of this, can we think in a pattern of social protection in the MERCOSUL? In this case, what are the possible transformations for social politics in the MERCOSUL? Which principles are necessary in order to assure social rights? Keywords: Social politics and national citizenship; states and MERCOSUL.
\end{abstract}

\section{Introdução}

Os elementos que definiram os Estados nacionais, a partir da teoria contratualista, como a organização política soberana, vinculada a uma população

\footnotetext{
* Doutora em Serviço Social pela Pontifícia Universidade Católica de São Paulo. Professora associada da Universidade Estadual de Ponta Grossa/Paraná. Endereço postal: Rua Manoel Fereira Pinto, 258, apt. 53, Centro, Ponta Grossa, Paraná, CEP: 84010660. Endereço eletrônico: cortesluci@gmail.com.
} 
constituída como povo sobre um território definido como espaço da nação sofrem sérios questionamentos com o processo de globalização. As transformações ocorridas na sociedade ocidental capitalista, especialmente a partir da segunda metade do século XX, indicam que esse modelo de Estado nacional (soberania, povo, território) já não se apresenta como realidade estável em várias regiões, sendo o caso mais claro de integração dos estados nacionais a formação da União Europeia. Na América Latina, o processo de construção de um modelo de Estado regional tornou-se evidente com a constituição do MERCOSUL.

As transformações sociais, políticas e econômicas alteram o modelo de Estado engendrado pela ordem burguesa. O eixo desse processo histórico é dado pelas transformações econômicas que envolvem a esfera produtiva, comercial e financeira. No campo político, verificam-se alterações no modelo de Estado nacional, dando início à construção de um sistema de poder regional no qual os Estados nacionais são considerados entes soberanos, mas vinculados entre si. Surge outro conceito de soberania, em contraposição à ideia da soberania absoluta dos Estados nacionais, cujo expoente teórico clássico pode ser considerado Thomas Hobbes (2001). A falta de limites ao poder soberano dos Estados nacionais, do ponto de vista das relações externas, levou às guerras mundiais do século XX: "O século XX foi o mais mortífero da história documentada" (HOBSBAWM, 2007, p. 21).

Com a possibilidade de organização de um sistema político supranacional, vários temas tornam-se problemáticos, tais como: a legitimidade das instituições supranacionais e o poder de representação dos cidadãos nas esferas políticas; o surgimento de um poder cogente acima dos Estados nacionais e a subordinação do poder estatal nacional à ordem internacional. No entanto, além da dimensão política relacionada à forma de organização institucional, das possibilidades de mecanismos democráticos de representação e participação, um ponto torna-se central, qual seja: a construção de um sistema de proteção social que opere no espaço supranacional e as possibilidades de superação do conceito clássico de cidadania, como vínculo jurídico centrado na nacionalidade. Seria possível e desejável a construção de um conceito de cidadania comunitária ou supranacional? Nesse sentido, cabe analisar a possibilidade de organizar, financiar e ter mecanismos de garantia de direitos relacionados à proteção social na esfera supranacional. A análise apresentada nesse texto parte de um raciocínio lógico dedutivo, das questões gerais para uma reflexão sobre a integração regional no contexto do MERCOSUL. Inicia-se a reflexão questionando as transformações no Estado moderno e sua base de legitimidade, bem como as funções que deve desempenhar e com qual finalidade deve atuar. Propõese um conjunto de questões a fim de levantar a problemática da construção de um modelo de organização política supranacional do ponto de vista da proteção social.

\section{O Sentido do Estado Moderno e o Problema da Nacionalidade}

O que é o Estado? Para responder a essa questão a polêmica é grande e complexa. Podemos partir da explicação dada pela teoria contratualista surgida na Europa com o fim da Idade Média e início das transformações políticas que culminaram nas revoluções americanas e francesas. Para os teóricos contratualistas, o Estado é o resultado de um pacto de vontade firmado entre os homens. Parte de um ponto 
de referência comum - a ideia de pacto - o debate sobre formação, legitimidade e limites do poder do Estado. Na contestação da legitimidade do poder divino, a teoria contratualista tem como ponto de referência para sua argumentação a ideia de um estado da natureza, pré-social, onde os homens são livres e iguais. Embora com sérias discordâncias sobre o que se entende por estado da natureza para Hobbes, Locke e Rousseau, há um consenso de que o Estado civil é a superação do estado da natureza. O Estado civil é o resultado da vontade dos homens que buscam superar as dificuldades, ameaças e incertezas do estado da natureza onde não há garantia de direitos.

Em Hobbes (2001), o pacto entre os homens cria o Estado como um poder acima de todos os súditos, sua alma é definida como soberania, que não encontra nenhum limite além do respeito ao inalienável direito à vida. Para Hobbes, o pacto que cria o Estado foi estabelecido entre os súditos - o Estado não participou do momento do pacto - e quem não participa do pacto não precisa cumpri-lo. Veja que, para tal autor, o Estado está acima do pacto, embora reconheça a sua origem nesse pacto fundador. Ao estabelecer que a origem do Estado é o pacto de vontade dos homens, Hobbes refuta toda proposta de legitimar o poder do Estado em razões di-vinas ou mesmo na transmissão do poder somente pela tradição ou por qualquer razão acima da vontade dos homens. Nesse sentido, Hobbes é um teórico do contratualismo e define o poder civil instituído pelo acordo de vontade dos homens como legítimo. Quanto aos limites do poder soberano, Hobbes, ao conceber a natureza do homem marcada por egoísmo, vaidade e competição, analisa que os homens tendem às paixões que podem levá-los à discórdia. Assim, o Estado é o senhor da conduta dos súditos e deve manter a todos em paz, usando da sua força para garantir a segurança. Se Hobbes dá um poder demasiado ao Estado, também é certo que o fim perseguido pelo Estado não é privado, mas sim coletivo: manter a paz. Hobbes identifica o individualismo e, como solução para evitar o conflito, ou guerra de todos contra todos, propõe que o Estado force os homens a viverem em paz pela construção do interesse coletivo. Veja que, para o autor, os bens a serem protegidos pelo Estado têm uma ordem de prioridade, sendo a vida o valor essencial, depois os afetos da vida em comum (família) e somente depois os bens materiais (propriedade). Se Hobbes constrói a proposta de um Estado soberano e com poderes absolutos, é também verdade que faz isso por considerar a gravidade dos conflitos que decorrem dos interesses privados.

O tema polêmico sobre o direito de propriedade fez com que Hobbes fosse criticado por Locke. Para Hobbes, a propriedade não é um direito natural, pois decorre do Estado civil. Portanto, é o Estado quem cria o direito de propriedade e assim quem cria pode também suprimir o direito criado. Nesse ponto surge a discórdia de John Locke, para quem o direito de propriedade é um direito natural, anterior à formação do estado civil. Devemos aqui considerar que Locke trabalha com conceito amplo de propriedade que envolve o direito à própria vida, à liberdade e aos bens produzidos pelo trabalho. Para Locke, o Estado civil é construído pelo pacto, mas, diferente de Hobbes, o Estado não cria o direito e sim as garantias para o exercício de direitos que já existiam no estado da natureza. Nesse sentido, o poder do Estado nunca será absoluto, sempre será submetido à vontade dos homens 
que pactuaram. Locke é o teórico contratualista que avança na formulação sobre o Estado de direito, aquele que, do ponto de vista interno, tem o poder soberano limitado pela lei. Decorre dessa concepção do poder do Estado, limitado pela lei, a proposta do Estado liberal. O Estado tem como função central a defesa dos interesses privados, da propriedade, pois o interesse coletivo resulta da ação dos agentes privados como uma consequência natural da busca pelos seus interesses.

Na polêmica sobre o estado civil, Rousseau parte do mesmo ponto de Hobbes e Locke ao considerar legítimo o Estado instituído a partir da vontade dos homens. Para Rousseau, o estado da natureza também aparece como momento pré-social, anterior à criação do Estado civil. Rousseau toma de Hobbes a consideração sobre os interesses coletivos. No entanto, dá uma nova interpretação para o pacto. Para tal autor, o Estado representa a soberania, mas a origem e o lugar da soberania não são o Estado e sim o povo. O povo é uma construção centrada na ideia do pacto que cria a sociedade entre os indivíduos. Portanto, nem todas as pessoas são integrantes do povo, somente aquelas que pactuaram. O estrangeiro não é parte do povo nem cidadão do Estado instituído por aquele povo. Para Rousseau, a propriedade é o ponto de discórdia entre os homens. Assim, o Estado civil tem o poder de controlar a propriedade para evitar os extremos de pobreza e riqueza. Como para Rousseau liberdade e igualdade são dois valores fundamentais, não se pode ter uma sociedade constituída por um pacto em que há extremos de riqueza e pobreza. Se o Estado for uma invenção do rico para oprimir o pobre (análise que Rousseau apresenta no texto do Discurso sobre a origem da desigualdade entre os homens), o pacto não será legítimo. Dessa forma, o Estado civil criado pelo pacto legítimo, pela vontade geral, tem que evitar os extremos entre riqueza e pobreza. Nesse ponto, podemos considerar que Rousseau se aproxima de Hobbes, para quem a propriedade não é um direito absoluto. Aqui aparece uma polêmica que já foi identificada por Hobbes, para quem o direito à vida é superior ao direito de propriedade. Hobbes ainda estabelece que o Estado tem a obrigação de socorrer o súdito quando este não encontrar trabalho ou meios de vida:

Por um acidente inevitável, sempre que muitos homens se tornam incapazes de se sustentar com seu trabalho, não devem ser deixados à caridade de particulares, mas ser supridos - tanto quanto as necessidades da natureza o exigirem - pelas leis do Estado. Assim como é falta de caridade, pois, também o é no soberano de um Estado expô-lo aos acasos de uma tão incerta caridade. (HOBBES, 2001, p. 252).

Rousseau, ao criticar a propriedade burguesa, estabelece ao Estado o dever de garantir um nível de igualdade entre os cidadãos, dando limites aos interesses privados. Podemos inferir das discussões de Rousseau que a legitimidade do Estado civil não decorre apenas da igualdade formal entre os homens que fazem o pacto é necessário um nível de igualdade substancial ou material entre os homens para que o pacto seja legítimo. 
Como crítica ao contratualismo, para Marx e Engels (1998), o Estado moderno é concebido, no texto do Manifesto do Partido Comunista, como o comitê da burguesia. O Estado formado pelo pacto cria uma igualdade formal que separa o homem em duas esferas contrapostas: de um lado surge o cidadão - conceito abstrato desvinculado das condições reais de vida dos homens; de outro lado, o homem concreto como membro de classes sociais distintas - como burgueses ou proletários. Marx e Engels, na análise do Estado, apontam os limites da democracia burguesa e do próprio conceito de cidadania. A função central do Estado é a defesa da ordem social, cujo suporte é a legitimidade da propriedade privada. Marx e Engels se esforçam para dar clareza ao conceito de propriedade burguesa, não como toda e qualquer propriedade de bens, mas como a propriedade dos meios de produção que subordinam a força de trabalho como trabalho assalariado, cujo emprego só existe se for capaz de gerar lucro e de bens cuja existência gera renda (exemplo: terra). Aqui reaparece a polêmica sobre o Estado, pois, da análise da realidade social do século XIX, em que não havia universalização de direitos políticos e nem expansão das funções do Estado na promoção de bens e serviços para as classes trabaIhadoras, o que salta como conclusão necessária para Marx e Engels é que o Estado existe para a defesa dos interesses privados das classes dominantes. No entanto, o dever ser do Estado para eles é a realização do interesse coletivo. Assim, surge a proposta da ditadura do proletariado - versão revolucionária da construção de um novo pacto, centrado na defesa dos interesses coletivos, cuja tarefa principal é abolir a propriedade burguesa. Na proposta revolucionária do comunismo, o Estado é um momento necessário para a construção de uma nova forma de sociabilidade entre os homens. O futuro da ditadura do proletariado é sua extinção, pois, quando o conflito entre interesse privado e interesse coletivo estiver superado, toda forma de dominação política deixará de ter razão para existir e então os homens poderão livremente se associar.

Para Marx e Engels, a transformação da sociedade em comunista não se realizará apenas pela abolição da propriedade privada, mas pela supressão de toda ordem burguesa - inclusive pela extinção da divisão do mundo em Estados nacionais. Essa é a tese que surge no Manifesto do Partido Comunista: num primeiro momento, o proletariado se une em cada Estado numa luta política contra a burguesia e sua forma política de dominação - o Estado nacional burguês -, para, ao existir como ditadura do proletariado, abolir as divisões de classe e a própria estrutura da sociedade organizada politicamente em Estados nacionais, pondo fim à cidadania burguesa. Assim, a existência do Estado nacional, na análise de Marx e Engels, é a forma política necessária ao desenvolvimento das forças produtivas capitalistas e, tanto quanto o capitalismo está marcado por uma contradição que leva à sua abolição no decurso da história. O Estado nacional opõe externamente os homens num conflito entre nações e, internamente, regula o conflito entre interesses privados e coletivos ou gerais.

\section{A Internacionalização da Economia e a Crise do Estado Nacional}

Ao tornar-se hegemônico, o sistema capitalista de produção aumentou de interdependência entre os diferentes agentes na sociedade. Ao produzir mercadorias 
(valor e uso e troca), prendeu todos numa cadeia de interdependência, pois a realização final do valor depende de condições do mercado. Assim, o trabalho tornouse efetivamente social, realizado num processo de produção cuja existência depende das condições de mercado.

Do ponto de vista de organização da economia nacional, o Estado desempenha o papel de garantidor das condições gerais da produção, estabelece a base legal para relação entre capital e trabalho, o sistema de proteção à propriedade privada, e o incentivo ao assalariamento da força de trabalho. Como agente que regula as relações sociais e interpessoais, o Estado cuida das normas de convivência e do controle estatal da violência por meio do sistema penal. Para os segmentos marginalizados do mercado de trabalho e da esfera produtiva, o Estado construiu uma rede de proteção social centrada na assistência social. Podemos concluir, a partir de Offe e Lenhardt (1984), que as funções do Estado são: garantir o assalariamento da força de trabalho como condição geral para o processo de acumulação do capital e a legitimidade da ordem social:

Sem a previdência social os meios e as instalações que servem para a cobertura dos riscos de trabalho e de vida seriam objeto de dispendiosas lutas redistributivas, ao passo que no quadro do sistema de previdência social eles são financiados por uma redistribuição obrigatória, horizontal e temporal, que gera confiança, e que alivia o capital, e não somente em termos financeiros. Surgindo um conflito em torno das condições desfavoráveis da existência do trabalhador assalariado, não se dá um confronto entre trabalhador e capital, nem se tornam objeto de conflito a organização capitalista do trabalho ou o nível salarial dela decorrente. O que poderia eventualmente provocar um conflito aberto de classe é transformado num conflito político ou numa controvérsia judicial. Os riscos e o tipo de elaboração desses conflitos são a priori definidos de tal forma que a estrutura do processo de produção capitalista não é posta em questão (OFFE e LENHARDT, 1984, p. 28).

O sistema de seguridade social, cujo eixo central é dado pelo sistema de previdência social, é definido em cada sociedade nacional pelo conjunto de fatores relacionados ao poder político de cada segmento da sociedade, pelo volume de recursos disponíveis na economia e pela capacidade de governança do aparelho burocrático do Estado.

Conforme Fleury (1994), a universalização do direito ao voto foi considerada por vários estudos um fator que favoreceu a formulação de acordos políticos que ampliaram o poder de negociação das classes trabalhadoras junto ao Estado, na luta pela conquista dos direitos sociais. Outra explicação para ampliação da atuação do Estado na área social que foi central foi a necessidade de regulação da economia, favorecendo a demanda por meio do consumo de massa e da ampliação dos gastos públicos, conforme análise de Lipietz (1992). 
O sistema de regulação da economia nacional mostrou-se, do ponto de vista externo, um mecanismo de proteção contra o poder de concorrência de outras economias. Assim, tensionado na luta entre interesses conflitantes, o Estado assume também, no âmbito internacional, o papel de garantidor das condições gerais da produção capitalista. O protecionismo é a marca geral da regulação do Estado em busca de preservar a economia nacional frente aos concorrentes externos.

No século XX, as crises do capital tiveram desfecho trágico, conforme os dados da crise de 1929, que afetou toda economia mundial, especialmente os países industrializados, levando ao desemprego milhares de trabalhadores. Deve-se considerar a ruptura política entre modelos de organização da produção a partir da Revolução Russa de 1917, que deu origem ao sistema soviético organizado por meio da União das Repúblicas Socialistas Soviéticas (URSS), antagonizando o modelo capitaneado pelos Estados Unidos da América do Norte. Os conflitos entre o modelo comunista (experiência real do URSS) e capitalista estiveram presentes nas disputas econômicas e políticas até o final da década de 1980, quando então houve o desmonte da URSS e a adesão das economias do Leste Europeu ao modelo de economia de mercado. Na URSS, mesmo que do ponto de vista interno o Estado tenha proibido a propriedade privada dos meios de produção, não destruiu a lógica da produção de mercadorias nem a concorrência externa. A luta econômica entre os países ocidentais e os países comunistas também se revelou como uma corrida por inovações tecnológicas e pelo poder de mercado.

Das crises econômicas, resultam também crises sociais e políticas. Pode-se estabelecer uma relação entre a forma de organização da economia capitalista, suas crises e as guerras mundiais do século XX, ao analisar o Estado na Alemanha, que, depois de assumir um pesado compromisso de reparação dos danos da Primeira Guerra Mundial levando à miséria milhares de pessoas, favoreceu o surgimento de um governo fascista que levou o mundo novamente à guerra.

Após a tragédia de duas grandes guerras, surge um conjunto de instituições de caráter supranacional: o Banco Mundial, o Fundo Monetário Internacional e a Organização das Nações Unidas. Foi o inicio do processo de construção de um sistema de poder supranacional, constituído por instituições que têm abrangência mundial e que tensionam o poder dos Estados nacionais. Para evitar a guerra de todos contra todos, esses organismos internacionais buscaram limitar as práticas protecionistas. Assim, podemos considerar que os fatores econômicos e geopolíticos redefiniram as relações entre os Estados nacionais, levando ao fim o sistema de colonização que ainda perdurava no século XX:

O período de 1945 até a Revolução Iraniana em 1979 presenciou o fim formal dos impérios coloniais holandês, inglês, francês, belga e português, com o surgimento de dezenas de Estados independentes na África e na Ásia, que pretendiam implementar políticas de desenvolvimento ativas (GUIMARÃES, 2003, p. 492).

O mapa geopolítico do mundo se redefine, assim como o poder de cada Estado dentro do sistema de poder mundial. O que surge não é um sistema demo- 
crático de poder no âmbito internacional, senão um mecanismo institucional de controle dos interesses em disputa no mercado mundial. Os Estados nacionais poderosos dominam o sistema político, uma vez que não existem mecanismos democráticos supranacionais.

A economia passou para uma fase de expansão que favoreceu o poder das empresas multinacionais que atuam num mercado global, sobrepondo-se em vários casos ao poder de regulação dos Estados nacionais. Ao final do século XX, a globalização torna-se a grande discussão, considerando os impactos desse processo na redefinição do sistema de poder no mundo, o poder de negociação do capital com o trabalho e o risco de marginalização de vastas regiões consideradas periféricas. ${ }^{1}$ Se, após a Segunda Guerra Mundial, a economia norte-americana tornou-se uma potência e o dólar a moeda de referência nas trocas internacionais, a Europa inicia um processo de resistência frente ao poder dos Estados Unidos com o Tratado de Roma, que deu início ao processo de formação da União Europeia (UE):

A UE ainda que represente modalidade avançada e profunda de integração econômica regional entre países convive com grandes diferenças entre os EM [Estados membros] - nações soberanas independentes. De acordo com os documentos europeus (Comisión Europea, 2000; Comisión Europea, 2005), os objetivos do mercado interno de livre competição, desenvolvimento sustentável, progresso científico e técnico, coesão econômica e social em ambiente de diversidade cultural e linguística impõem a transferência de poderes nacionais para a UE (GUIMARÃES e QUEIROZ, 2007, p. 43).

Podemos verificar, a partir da criação da Comunidade Europeia, as transformações do Estado de um poder político nacional soberano para a construção de um modelo regional.

A concorrência econômica e geopolítica entre as potências européias e a norte-americana, especialmente após a Segunda Guerra Mundial, levou os demais países a adotarem também medidas protecionistas. Esse processo de transformação política pode ser analisado a partir da nova base de organização da produção e do novo patamar de concorrência estabelecido pela adoção da microeletrônica e da tecnologia de comunicação via satélite. Com a retomada, no plano político, das ideias liberais, a partir da década de 1980, o capital avança no processo de internacionalização, liberando-se das amarras do controle estatal, especialmente na área financeira. América Latina, África e regiões da Ásia passaram a temer o aprofundamento da desigualdade entre os países desenvolvidos e os considerados periféricos - o conflito anterior que polarizou o mundo capitalista e o comunista foi substituído pelo conflito Norte e Sul.

Kenichi Ohmae (1996) anunciou O fim do Estado nação a partir da ascensão das economias regionais. Ganha destaque os acordos internacionais de cooperação

\footnotetext{
${ }^{1}$ Uma análise mais detalhada desse processo pode ser encontrada em COSTA, L. C. (2006).
} 
econômica e a busca por um novo sistema de poder geopolítico para fazer resistência à polarização Norte/Sul. Na América Latina, houve tentativas de integração regional que precederam o MERCOSUL, sem, no entanto, lograr êxito. Somente ao final da década de 1980, o Brasil e a Argentina retomam as discussões para a formação de um bloco econômico e, finalmente em 1991, os presidentes de Brasil, Argentina, Paraguai e Uruguai assinaram o Tratado de Assunção, criando o MERCOSUL. Os objetivos expressos com a criação do MERCOSUL estavam relacionados à busca pela am-pliação do comércio na região e a adoção de estratégias defensivas frente ao poder dos países ricos.

Com a regionalização do mundo em blocos econômicos, o Estado nacional passa então por sérios questionamentos: como manter, do ponto de vista da legitimidade, um sistema de poder supranacional? Como desenvolver mecanismos de controle de conflitos que extrapolam o Estado nacional e colocam a necessidade de instituições com poder cogente do ponto de vista supranacional? Caso o Estado, tal como foi justificado pela teoria contratualista e depois pela teoria liberal, perca a relação de legitimidade com os cidadãos que dele fazem parte, como poderá manter a ordem capitalista? Terá então o Estado assumido seu caráter essencialmente burguês agora que a globalização já extrapolou os limites da organização nacional da economia? A tese de $O$ manifesto comunista parece tornar-se realidade conclamando os trabalhadores do mundo a se unirem contra as forças do capital, levando à derrocada a fórmula política do Estado nacional. Por certo, a união dos trabalhadores deve se dar em busca da superação da sociedade de classes e da expressão nacionalista dos interesses econômicos do capitalismo. Conforme David Harvey:

A governabilidade para o capitalismo contemporâneo envolveu a instauração de importantes autoridades supranacionais como o NAFTA (Acordo Norte-amerciano de Livre Comércio) e a União Europeia. Essas instituições, que têm o Acordo de Maastricht como caso paradigmático, são inquestionavelmente pró-capitalistas. Como deveria a esquerda reagir? [...] Refugiar-se na nação-Estado como lugar estratégico exclusivo da organização e da luta de classes é cortejar o fracasso (assim como flertar com o nacionalismo e tudo aquilo que ele envolve). Isso não significa que a nação-Estado tenha se tornado irrelevante - na realidade, ela está mais relevante do que nunca. Mas a escolha da escala espacial não é uma questão de "ou isto ou aquilo", mas de "tanto isto como aquilo", ainda que esta última opção esteja eivada de sérias contradições (HARVEY, 2004, p. 75).

\section{A Internacionalização da Proteção Social}

\section{como Fator de Legitimação da Ordem Supranacional}

A globalização promoveu uma drástica ruptura dos controles e limites para a livre circulação do capital. No entanto, os blocos regionais, como construções políticas, enfrentam o desafio de também liberar a circulação de pessoas. No caso da União Europeia: 
a evolução das medidas relativas à livre circulação de pessoas: começaram por medidas para garantir a mobilidade dos trabaIhadores dentro da Comunidade, continuaram por medidas de proteção aos trabalhadores (nomeadamente as mulheres), e hoje incluem medidas a respeito da circulação de todas as pessoas, sobre imigração legal e ilegal, e sobre asilo (D'ARCY, 2001, p. 137).

Assim, o trabalho também sofre o impacto do processo de internacionalização, podendo circular livremente pelo bloco econômico com a formação de um mercado comum. ${ }^{2}$ Dessa forma, coloca-se o desafio de integrar o sistema de proteção social, pois, longe de ser apenas uma garantia de direitos para o trabalhador, todo sistema legal que regula a força de trabalho incide no nível de competitividade de cada economia nacional. Se não houver uma homogeneização ou ao menos uma padronização do sistema de proteção social, haverá migrações de trabalhadores em busca de melhores condições de vida para os Estado onde há melhor padrão de proteção social.

O problema do financiamento do sistema de proteção social e os mecanismos legais para o acesso aos direitos protetivos inserem-se no debate sobre a formação dos blocos regionais. A cidadania, compreendida como vínculo jurídico que liga o indivíduo ao Estado, é o critério inicial exigido para acesso ao sistema de proteção social na esfera nacional. Com a integração dos Estados nacionais por meio da constituição de um mercado comum, esse conceito de cidadania é questionado, passase a discutir sobre a possibilidade de um conceito de cidadania comunitária ou supranacional. Conforme D'Arcy (2001), o debate sobre a dimensão social da Comunidade Europeia evidencia que não há interesse de uma solidariedade financeira entre os Estados para financiar os custos da proteção social:

No caso da proteção social, uma reflexão muito ampla está se desenvolvendo sobre os principais problemas e desafios aos quais os sistemas nacionais estão confrontados e sobre as melhores soluções; destaca também a grande diversidade dos sistemas nacionais de proteção social e o fato que não seja possível nem necessário harmonizá-los. Essa diversidade, bem como a aplicação do princípio de subsidiariedade, são geralmente invocadas para limitar a intervenção comunitária neste domínio (D'Arcy, 2001, p. 141).

Ao mudarem-se os critérios para definir cidadania, superando a questão da na-cionalidade, surge o questionamento sobre os fundamentos dos direitos humanos

\footnotetext{
${ }^{2}$ O MERCOSUL ainda não constitui um mercado comum, embora tenha declarado esse objetivo programático desde sua criação. Na realidade constitui uma área de livre-comércio e união aduaneira, com medidas relacionadas à adoção de tarifa externa comum, embora persistam conflitos com os acordos bilaterais que os Estados-parte fazem com parceiros fora do bloco.
} 
e sua amplitude. Ao afirmar os direitos humanos acima dos direitos de cidadania, segundo FERRAJOLI (2006), derruba-se a barreira que a burguesia colocou como limite para o acesso ao sistema de proteção social, restrito aos nacionais. A expansão do acesso aos direitos sociais funcionou como mecanismo de legitimação da ordem burguesa na esfera do Estado nação - agora tal problemática se coloca na esfera supranacional. Para garantir a legitimidade dessa ordem política, torna-se necessária a incorporação de demandas de proteção social que favoreçam o assalariamento da força de trabalho no espaço do mercado comum, num patamar que possibilite regras gerais para o capital.

A partir da realidade já evidente da formação dos blocos regionais, questionase a capacidade das teorias que analisaram a intervenção do Estado nacional na regulação dos conflitos entre capital e trabalho para explicar essa nova formação política supranacional. No campo das ciências políticas e sociais, o desafio é analisar as funções do Estado a partir do processo de integração regional com a emergência de um mercado comum, com circulação de pessoas.

Numa abordagem dentro do campo jurídico e sociológico, a teoria garantista, ao analisar a construção de uma nova ordem social que supere os Estados nacionais, considera os direitos humanos, algo fundamental, acima dos direitos de cidadania, conforme Ferrajoli:

Levar a sério aqueles valores, ou seja, os dos direitos humanos proclamados pelas cartas constitucionais, significa consequentemente ter a coragem de desancorá-los da cidadania, ou seja, desvencilhá-los do último privilégio de status que permaneceu no direito moderno. E isso significa reconhecer seu caráter supraestatal, garanti-los não apenas dentro, mas também fora e contra todos os Estados, e assim dar um fim a esse grande apartheid que exclui do seu aproveitamento a maioria da humanidade (FERRAJOLI, 2002, p. 58).

A teoria do garantismo, segundo Ferrajoli (2006), realiza a crítica ao formalismo presente no Estado, apontando a distância existente entre as normas válidas e vigentes e sua eficácia, bem como denunciando a ilegitimidade das práticas que contrariam as normas. Do ponto de vista do garantismo, o Estado de direito, como um governo subordinado às leis e que age por leis gerais e abstratas, deve considerar a legalidade sob o ponto de vista formal e substancial. A legalidade formal refere-se ao respeito às leis gerais e abstratas, os limites ao poder do Estado e a defesa da liberdade dos indivíduos, que são as obrigações negativas no sentido de um nãofazer do Estado, uma abstenção. Enquanto a legalidade substancial refere-se à capacidade de efetivar os direitos, incluindo os direitos sociais como obrigação positiva do Estado - exige um fazer do Estado, uma prestação.

Para essa teoria, o Estado democrático de direito deve garantir os direitos fundamentais, sob pena de perder a legitimidade. O problema da democracia como forma de governo questiona quem decide e como decide. A democracia substancial foca a análise sobre a dimensão das decisões, sobre o que se deve decidir. 
Do ponto de vista da democracia substancial, o desafio é efetivar os direitos declarados, adequar as normas às práticas legitimas, superar o formalismo presente no Estado de direito e dar garantias aos direitos fundamentais declarados, tendo o ponto de vista da crítica externa ao sistema normativo. Isso implica colocar sob questão o próprio direito e o modelo de Estado liberal. Dessa forma, surge o desafio de transpor para um modelo de Estado supranacional os mecanismos do Estado democrático de direito e exigir garantias, como mecanismos normativos, para assegurar a máxima correspondência entre normatividade e efetividade da tutela dos direitos.

A formação dos blocos regionais se deu como uma estratégia de defesa de interesses comerciais num mercado globalizado. Tal estratégia pode levar a uma crise de legitimidade se o Estado nacional enfraquecer sua atuação na proteção social. Para manter a legitimidade do sistema de poder político, a formação dos blocos regionais deve superar o formalismo das declarações que propugnam pelo desenvolvimento com justiça social. Nesse sentido, é preciso criar mecanismos de proteção social que atuem de forma regional. Torna-se evidente a necessidade de travar uma luta pela proteção social também na esfera supranacional, num contexto em que se avança no sentido de formar um mercado comum, pois a livre circulação de pessoas deve ser acompanhada pela internacionalização do sistema de proteção social.

O MERCOSUL, criado em 1991, não teve inicialmente nenhuma proposta na área da proteção social. Somente em 1998, com a declaração sociolaboral, o tema da proteção social ganhou destaque. Embora no campo das declarações o MERCOSUL tenha dado evidência à agenda social nas últimas cúpulas governamentais, no campo da efetividade das normas não houve avanço significativo. Assim, é preciso questionar a legitimidade do MERCOSUL a partir de suas próprias declarações e exigir a criação de mecanismos que deem garantias para efetivar os direitos proclamados. A partir da construção de uma agenda social, é preciso construir um sistema de garantia de direitos no MERCOSUL.

\section{A Declaração Sociolaboral e a Agenda Social do MERCOSUL}

Em 10 de dezembro de 1998, os presidentes dos Estados - parte assinaram a Declaração Sociolaboral, colocando o tema da proteção social em discussão dentro do MERCOSUL. A referida declaração criou a Comissão Sociolaboral, órgão tripartite, auxiliar do Grupo Mercado Comum, que terá caráter promocional e não-sancionador, dotado de instâncias nacionais e regional, com o objetivo de fomentar e acompanhar a aplicação do instrumento.

A Declaração Sociolaboral, em seus 25 artigos, estabelece um conjunto de princípios e direitos na área do trabalho, que devem ser respeitados pelos Estadosparte no sentido de criar um padrão de proteção social ao trabalhador no bloco regional. Entre os direitos previstos, destaca-se a não-discriminação:

Todo trabalhador tem garantida a igualdade efetiva de direitos, tratamento e oportunidades no emprego e ocupação, sem distinção ou exclusão por motivo de raça, origem nacional, cor, sexo ou orientação sexual, idade, credo, opinião política ou sindical, ideologia, posição econômica ou qualquer outra con- 
dição social ou familiar, em conformidade com as disposições legais vigentes.

A proteção ao trabalhador migrante ou fronteiriço está prevista na declaração conforme segue:

Todo trabalhador migrante, independentemente de sua nacionalidade, tem direito à ajuda, informação, proteção e igualdade de direitos e condições de trabalho reconhecidos aos nacionais do país em que estiver exercendo suas atividades, em conformidade com a legislação profissional de cada país.

No campo da seguridade social, a declaração prevê:

1) Os trabalhadores do MERCOSUL têm direito à seguridade social, nos níveis e condições previstos nas respectivas legislações nacionais.

2) Os Estados-parte comprometem-se a garantir uma rede mínima de amparo social que proteja seus habitantes frente à contingência de riscos sociais, enfermidades, velhice, invalidez e morte, buscando coordenar as políticas na área social, de forma a suprimir eventuais discriminações derivadas da origem nacional dos beneficiários.

A partir da Declaração Sociolaboral de 1998, realizaram-se várias reuniões para a elaboração de uma agenda social para o MERCOSUL, conforme segue: VII Reunião de Ministros e Autoridades do Desenvolvimento Social do MERCOSUL, Bolívia, Chile e Peru (Brasília, 9 de dezembro de 2004); Declaração de Assunção "Rumo a um MERCOSUL Social como Instância Articuladora das Políticas Sociais na Região" (Assunção, 1ํ de junho de 2005); Declaração de Montevidéu (Montevidéu, 25 de novembro de 2005); Declaração de Buenos Aires "Por um MERCOSUL com Rosto Humano e Perspectiva Social" (Buenos Aires, 14 de julho de 2006).

Podemos analisar que a legitimidade do MERCOSUL passa pela criação de mecanismos que incorporem e garantam níveis de proteção social. No entanto, o que se pode perceber a partir dos documentos e declarações do MERCOSUL é que, num primeiro momento da integração regional fomenta-se que cada Estado-parte adote medidas de proteção social para seus cidadãos e que se harmonize a legislação trabalhista e previdenciária. Não se coloca ainda a construção de um conceito comunitário de cidadania, pois a vinculação dos direitos sociais ainda se dá para o cidadão de cada Estado nacional. O que se coloca de forma evidente no âmbito do MERCOSUL é a transposição de um modelo de proteção dado pela condição de trabalho e não pela ampliação de um conceito de cidadania, pois o trabalhador do MERCOSUL é definido como aquele que tem vínculo de emprego com empresas que atuam no espaço do bloco, podendo deslocar a força de trabalho nos diferentes Estados. Assim, é pelo estatuto do trabalho, e não pela prevalência dos direitos humanos, que se está construindo a proteção ao trabalhador do MERCOSUL. Nesse ponto, podemos considerar que a proteção social, ao estar vinculada à definição do 
trabalhador do MERCOSUL, é uma medida regressiva frente ao conceito de direitos sociais definidos em função da condição de cidadania. Não é por ser cidadão do MERCOSUL que se tem acesso aos direitos sociais do trabalho, mas pelo vínculo de emprego.

Os princípios e direitos do trabalho referem-se a intenções e esforços para que cada Estado-parte garanta aos seus cidadãos um patamar de proteção comum. É a discussão de um universalismo básico (MOLINA, 2006), e não a transposição da barreira da cidadania para a formulação da proteção social como um direito humano, que se torna evidente no MERCOSUL.

Podemos analisar o processo de luta pela proteção social no MERCOSUL sob dois pontos de referência: de um lado, a legitimidade do MERCOSUL foi questionada ao ter seus objetivos definidos apenas no campo econômico comercial, o que levou ao surgimento da Declaração Sociolaboral e da agenda social; de outro lado, esses documentos ainda não avançaram na construção de mecanismo para garantir a efetividade dos direitos declarados. Como resultado imediato do debate sobre a importância da proteção social no bloco, houve a ampliação da estrutura institucional do MERCOSUL. Podemos compreender que tal estrutura está em processo de formação; assim, a expansão dos grupos de trabalho e dos espaços de debates sobre a proteção social já sinalizam um avanço na construção de políticas sociais de caráter regional. Conforme o relatório final da Reunião do MERCOSUL de 2006, o tema da proteção social deve ganhar destaque na busca de uma integração regional com elevação dos níveis de desenvolvimento social:

La superación de la concepción economicista que ingenua o interesadamente se le pretende asignar al MERCOSUR y su reemplazo por una visión más amplia, que incluya las dimensiones productiva, cultural, educativa, social y política, que garantice el desarrollo de sociedades integradas y equitativas social y territorialmente, es precisamente uno de los grandes desafíos que enfrentan los países que componen el bloque regional (MERCOSUR, 2006, p. 11).

\section{Considerações Finais}

Podemos afirmar que existe um processo de transformações no mundo ocidental capitalista, evidente com a formação dos blocos regionais e com a criação de instituições políticas de caráter supranacional. Nesse sentido, o Estado nacional tem suas funções redefinidas conforme se insere na formação de bloco regional voltado para construção de mercado comum em que deve prevalecer a livre circulação de fatores (capital e força de trabalho). A função do Estado na formulação da política monetária nacional e a formulação de políticas macroeconômicas foram redefinidas com a criação do mercado comum, no caso da União Europeia. Segundo D'Arcy (2001), a medida de maior destaque foi dada pela adoção do Euro, moeda comum, que limita os instrumentos das políticas macroeconômicas nacionais e a criação do Banco Central Europeu, que tem a responsabilidade de conduzir a política monetária, como uma instituição independente dos governos nacionais. 
Ao possibilitar a circulação de pessoas, expande-se a demanda por proteção social para além dos limites do Estado nacional. Para atender a essa configuração política supranacional, é preciso instituições legítimas que estabeleçam marco regulatório e mecanismos de garantias para os direitos de proteção social.

O conceito de cidadania vinculado à nacionalidade se mostra limitado na luta pela proteção social num mundo onde se formam blocos regionais. Considerado do ponto de vista interno de cada Estado nacional, o conceito de cidadania representa um avanço na luta pelo acesso aos direitos sociais, desvinculando a proteção social do estatuto do trabalho. Já, do ponto de vista externo, o conceito de cidadania se mostra como uma barreira ao acesso à proteção social, uma vez que exclui o não-nacional, considerado não-cidadão. Assim, surge o questionamento sobre as limitações desse conceito quando se trata de construir uma proteção social de caráter supranacional. É preciso avançar na proteção social a partir da garantia e efetividade dos direitos fundamentais como direitos humanos, considerados um sistema composto por direitos de liberdade, sociais e de convivência.

Podemos pensar que os desafios colocados ao processo de integração regional são muitos, pois a América Latina tem um passado de governos autoritários, ausência de mecanismos que garantam o acesso aos direitos sociais na esfera nacional de cada país. No MERCOSUL, a desigualdade social, econômica e política dos Estadosparte é grande, levando a uma assimetria nos níveis de proteção dentro de cada sociedade nacional. Assim, é preciso elevar o nível de proteção social nos países onde os mecanismos de garantia ainda são débeis, especialmente no caso do Paraguai e, de outro lado, elevar a efetividade dos direitos nos países onde já existem normas e instituições voltadas para a proteção social. O Brasil se insere nesse segundo caso, no qual o que se busca é avançar na efetividade dos direitos que são previstos em normas legais e existem instituições públicas voltadas para sua garantia. Aqui, a teoria garantista pode ser útil na análise sobre a legitimidade do Estado, pois, do ponto de vista formal, podemos concordar que o Brasil já constitui Estado democrático social de direito, mas do ponto de vista da legitimidade substancial, há uma grande distância entre a normatividade e a efetividade da tutela dos direitos.

O tema da proteção social questiona a legitimidade do MERCOSUL Como um acordo comercial originado pela decisão dos governos dos Estados-parte. Segundo a teoria contratualista, o Estado legitimo surge do consentimento dos governados. Nesse sentido, é preciso indagar sobre os interesses que levam os governados a consentir com a formação de um Estado supranacional, sob pena de perda de sua legitimidade. Para que o MERCOSUL seja legitimado pela sociedade civil, ele não pode permanecer como uma esfera de decisões governamentais voltada para garantir interesses econômicos. Deve-se avançar nos mecanismos que garantam sua legitimidade, o que coloca no centro do debate os objetivos de proteção social. $\mathrm{Se}$, na origem, o MERCOSUL teve um caráter comercial, voltado apenas aos interesses do crescimento econômico, como instituição política não pode permanecer como um comitê da burguesia regional. A luta pela proteção social já está inserida na esfera supranacional, pois, ao internacionalizar a economia, também se expandem seus conflitos. Conforme a análise de Marx e Engels (1998), os proletários do mundo devem se unir. No entanto, o chamado à união dos proletário, continua 
atual, mas não pode ser pensado nos moldes do século XIX - não se podem pleitear direitos que sejam vinculados apenas à condição de trabalho e muito menos ao vínculo com o mercado formal de trabalho. Conforme analise de David Harvey (2004), a luta dos trabalhadores, que ainda expressa conflitos de classe, tem a potencialidade de propor uma mudança radical na defesa dos direitos humanos e desse modo assume um caráter de luta contra a lógica do capital que opera em escala mundial. 


\section{Referências Bibliográficas:}

COSTA, Lucia Cortes da. Integração regional e proteção social no contexto do MERCOSUL. In: MENDES, Jussara Maria Rosa et al. (orgs.). MERCOSUL em múltiplas perspectivas: fronteiras, direitos e proteção social. Porto Alegre: EDIPUCRS, 2007.

. Os impasses do Estado capitalista: uma análise da reforma do estado no Brasil. São Paulo: Ponta Grossa/Cortez: Editora UEPG, 2006.

D'ARCY, François. Considerações sobre a União Européia para servir nas reflexões sobre o MERCOSUL. In: LIMA, Marcos Costa (org.). O lugar da América do Sul na nova ordem mundial. São Paulo: Cortez, 2001. FERRAJOLI, Luigi. A soberania no mundo moderno. São Paulo: Martins Fontes, 2002.

. Direito e razão. Teoria do garantismo penal. São Paulo: Editora Revista dos Tribunais, 2006.

FLEURY, Sônia. Estado sem cidadãos. Seguridade social na América Latina. Rio de Janeiro: FIOCRUZ, 1994.

GUIMARÃES, Luisa e QUEIROZ, Vinicius Pawlowski. Integração europeia e acordos fronteiriços em saúde na euroregião de Extremadura - Alentejo. In: MENDES, Jussara Maria Rosa Mendes et al. (orgs.). MERCOSUL em múltiplas perspectivas: fronteiras, direitos e proteção social. Porto Alegre: EDIPUCRS, 2007. GUIMARÃES, Samuel Pinheiro. Globalização, guerra e violência. In: NOVAES, Adauto (org.). A crise do Estado nação. Rio de Janeiro: Civilização Brasileira, 2003.

HARVEY, David. Espaços de esperança. São Paulo: Edições Loyola. 2004. HOBBES, Thomas. O Leviatã, ou matéria, forma e poder de um Estado eclesiástico e civil. São Paulo: Martin Claret, 2001. HOBSBAWM, Eric. Globalização, democracia e terrorismo. São Paulo: Cia das Letras, 2007.

LIPIETZ, AI. Towards a new economic order: postfordism, ecology and democracy. New York: Oxford University Press, 1992.

LOCKE, John. O segundo tratado do governo civil. São Paulo: Abril, 2001 (Col. Os Pensadores).

MARX, K. ENGELS, F. O Manisfesto Comunista. Rio de Janeiro: Paz e Terra, 1998.

MERCOSUL. Declaração Sociolaboral. Brasil, 1998.

MERCOSUR. La dimension social del MERCOSUR. Reunión de Ministros y Autoridades de Desarrollo del MERCOSUR y Estados asociados. Argentina, Julho de 2006. Disponível em http://www.forumsocialdomercosul.org/.

MOLINA, Carlos Gerardo. Universalismo básico. Uma Nueva política social para América Latina. Banco Interamericano de Desarrollo. Washington: Editorial Planeta, 2006.

OFFE, C. e LENHARDT, G. Teoria do estado e política social. In: OFFE, Claus. Problemas estruturais do Estado capitalista. Rio de Janeiro: Tempo Brasileiro, 1984. 
OHMAE, Kenichi. O fim do estado nação. A ascensão das economias regionais. Rio de Janeiro: Campus, 1996.

ROUSSEAU, Jean Jacques. O contrato social. São Paulo: Abril, 1978 (Col. Os Pensadores).

SOUZA, Marcelo Medeiros Coelho de. A transposição de teorias sobre a institucionalização do welfare state para o caso dos países subdesenvolvidos. Texto para discussão, n. 695. Rio de Janeiro: IPEA, 1999.

Recebido em 20 de março de 2009.

Aceito para publicação, em 05 de junho de 2009. 